\title{
Gastric subcentimeter subepithelial tumor: successful resection with an over-the- scope padlock clip
}

A 60-year-old woman was referred for endoscopic resection of two 5-mm gastric subepithelial lesions (> Fig. 1) incidentally found during a screening endoscopy. Abdominal computed tomography (CT) revealed no lesions. The lesions were hypoechoic and originated from the muscle layer on endoscopic ultrasonography and were undetected on the endoscopy performed 5 years before. Follow-up was advised owing to the small lesions, but the patient requested an endoscopic resection to further clarify the nature of the tumor.

Endoscopy was performed after coagulation marking on the lesion ( $\mathbf{F i g . 1}$, right). Two padlock clips (Steris, Mentor, Ohio, USA) were placed after suction of the targeted lesions ( $\triangleright$ Fig. 2 , left). The lesion with the overlying mucosa was removed using single-step hot snare resection (> Fig.2, right; $>$ Video $\mathbf{1}$ ). Both tumors were completely resected ( Fig.3). Abdominal radiography revealed no perforation ( $\triangleright$ Fig.4). The patient received a restricted diet and was discharged the next day. Pathological examination revealed that the lesion from the gastric cardia was a gastrointestinal stromal tumor [CD $117(+)$, Dog1 $(+)$, CD $34(+)$, desmin $(-)$, and S-100(-)] and the other one from the body was a leiomyoma [CD $117(-), \operatorname{Dog} 1(-)$, CD 34 $(-)$, desmin $(+)$, and S-100 (-)].

A subepithelial lesion of the stomach is a common incidental finding during endoscopy especially for lesions $<2 \mathrm{~cm}$ in size $[1,2]$. Surveillance endoscopy is recommended owing to the low risk of disease progression, but patient compliance is poor [3]. Leiomyoma and gastrointestinal stromal tumor (GIST) are the two leading causes of subepithelial lesions arising from the muscle layer. While leiomyomas are almost benign, larger GISTs have a malignant potential. Endoscopic or radiological differentiation of the two conditions is difficult as demonstrated in this case. Several endoscopic
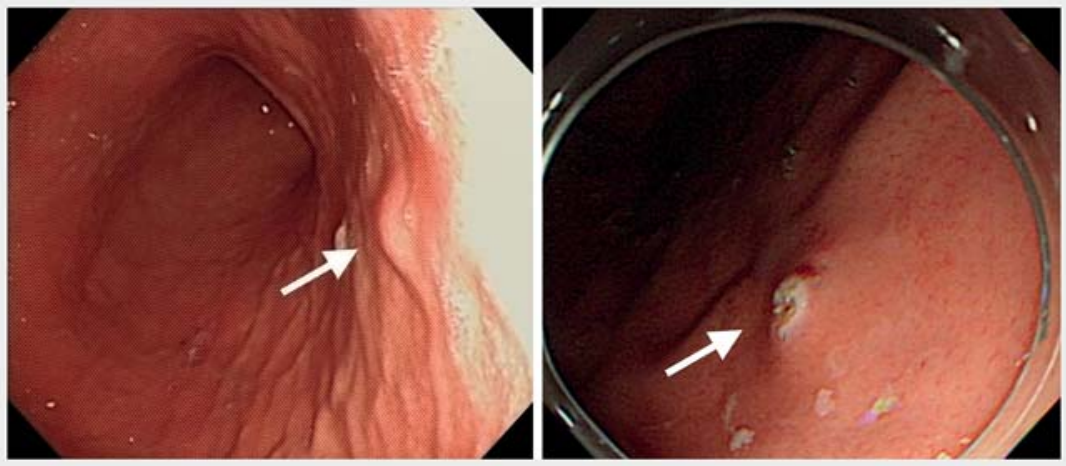

Fig. 1 Endoscopic view of the gastric subepithelial lesions. Left: middle body posterior wall. Right: gastric cardia.
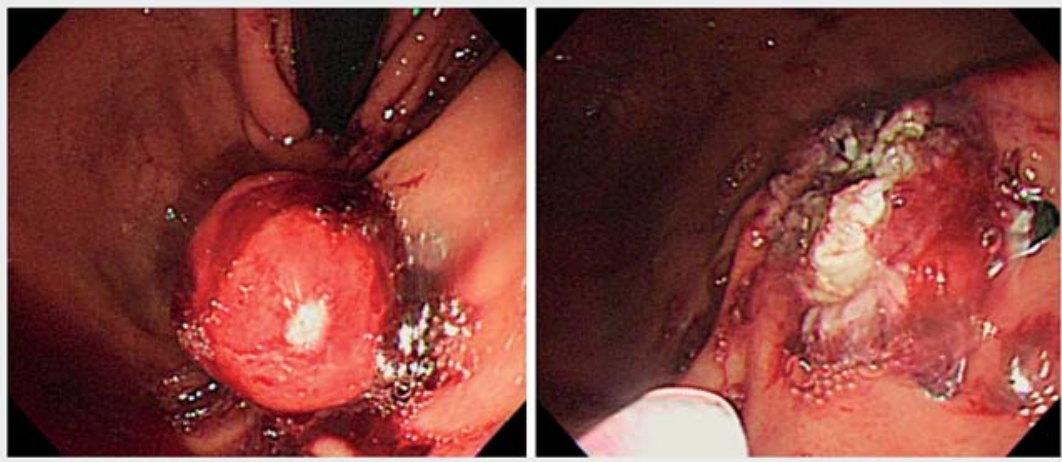

Fig. 2 Endoscopic view of the resection process. Left: ligation of the lesion with a padlock clip. Right: endoscopic view after resection of the tumor.
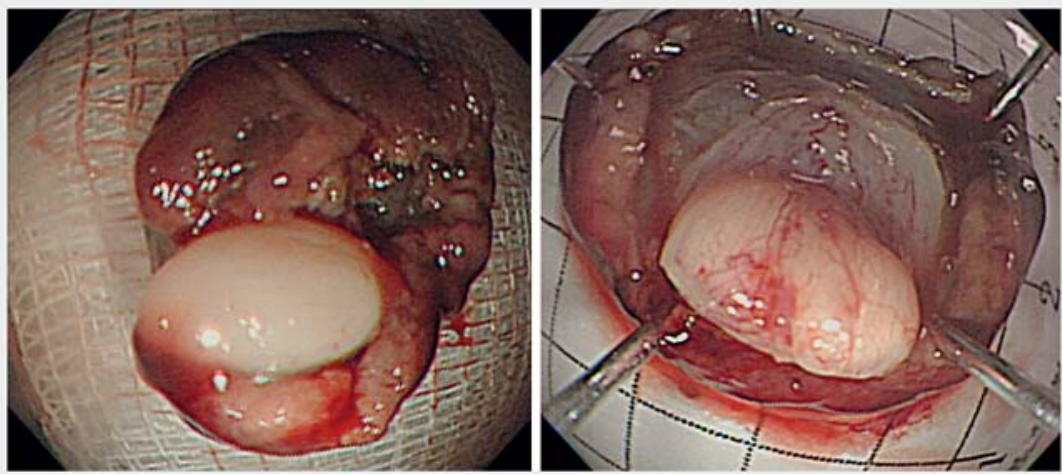

Fig. 3 Endoscopic view of the resected specimen. Left: body. Right: gastric cardia. 


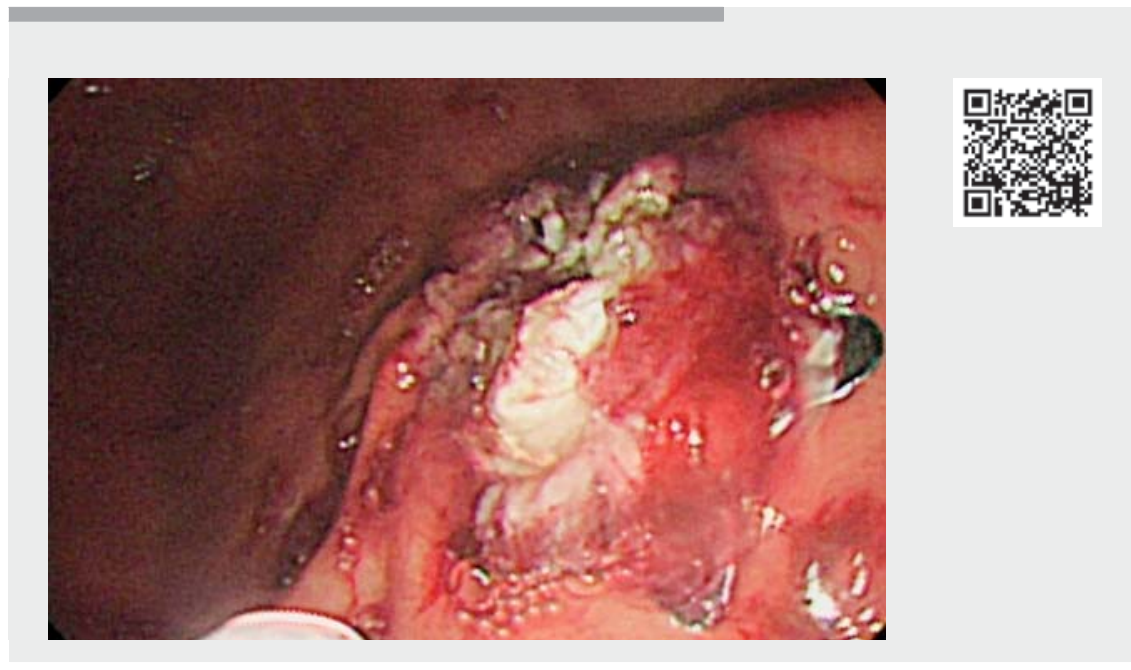

Video 1 Successful resection of gastric subcentimeter subepithelial tumor with an over-the-scope padlock clip.

resection techniques were proposed for such lesions but are technically demanding [1], with a high perforation risk. This case demonstrates the usefulness of over-the-scope clips [4] as an easy treatment method for small subepithelial lesions.

Endoscopy_UCTN_Code_TTT_1AO_2AG

Funding

Changhua Christian Hospital,

http://dx.doi.org/10.13039/

501100007632

109-CCH-IRP-008

\section{Competing interests}

The authors declare that they have no conflict of interest.

\section{The authors}

\section{Hsu-Heng Yen ${ }^{1,2,3}$, Hui-Ting Hsu ${ }^{4}$}

1 Endoscopy Center, Division of Gastroenterology, Changhua Christian Hospital, Changhua, Taiwan

2 General Education Center, Chienkuo Technology University, Changhua, Taiwan

3 Department of Electrical Engineering, Chung Yuan Christian University, Chung Li, Taiwan
4 Department of Surgical Pathology, Changhua Christian Hospital, Changhua, Taiwan

\section{Corresponding author}

\section{Hsu-Heng Yen, MD}

Division of Gastroenterology, Changhua Christian Hospital, 135 Nanhsiao St. Changhua 500, Taiwan

\section{References}

[1] Aslanian HR, Sethi A. ASGE Technology Committee. et al. ASGE guideline for endoscopic full-thickness resection and submucosal tunnel endoscopic resection. VideoGIE 2019; 4: 343-350

[2] Faulx AL, Kothari S. Standards of Practice Committee. et al. The role of endoscopy in subepithelial lesions of the GI tract. Gastrointest Endosc 2017; 85: 1117-1132

[3] Kushnir VM, Keswani RN, Hollander TG et al. Compliance with surveillance recommendations for foregut subepithelial tumors is poor: results of a prospective multicenter study. Gastrointest Endosc 2015; 81: 13781384

[4] Suthar D, Kramer EH, Khara HS. Successful endoscopic removal of toothpick perforating gastric antrum with over-the-scope padlock clip closure. Cureus 2020; 12: e11263 blaneyen@gmail.com

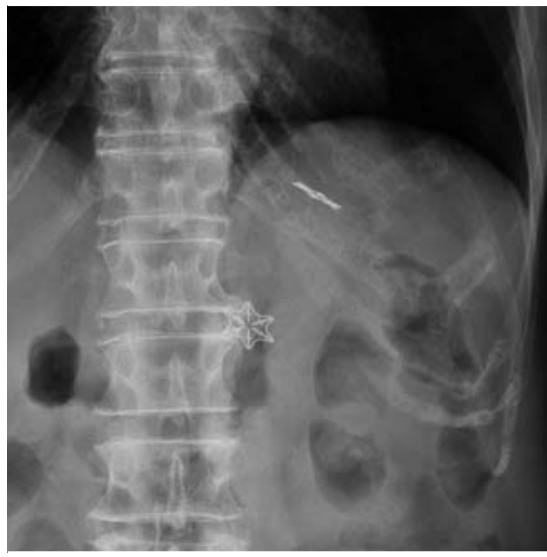

- Fig. 4 Abdominal X-ray after placement of two padlock clips.

\section{Bibliography}

Endoscopy 2022; 54: E238-E239

DOI 10.1055/a-1493-2004

ISSN 0013-726X

published online 8.6.2021

(c) 2021. Thieme. All rights reserved.

Georg Thieme Verlag KG, Rüdigerstraße 14,

70469 Stuttgart, Germany

\section{ENDOSCOPY E-VIDEOS}

https:|/eref.thieme.de/e-videos

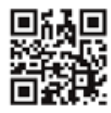

Endoscopy E-Videos is an open access online section, reporting on interesting cases and new techniques in gastroenterological endoscopy. All papers include a high quality video and all contributions are freely accessible online. Processing charges apply (currently EUR 375), discounts and wavers acc. to HINARI are available.

This section has its own submission website at

https://mc.manuscriptcentral.com/e-videos 